\title{
Catching up! The sexual behaviour and opinions of Italian students (2000-2017)
}

\author{
Alessandra Minello ${ }^{1 *}$ (D), Marcantonio Caltabiano ${ }^{2}$, Gianpiero Dalla-Zuanna ${ }^{3}$ and Daniele Vignoli ${ }^{1}$
}

\author{
* Correspondence: alessandra. \\ minello@unifi.it \\ ${ }^{1}$ Department of Statistics, Computer \\ Science, Applications "G. Parenti" \\ (DiSIA), University of Florence, Viale \\ Morgagni 59, 50134 Florence, Italy \\ Full list of author information is \\ available at the end of the article
}

\begin{abstract}
While sexuality has radically changed across middle-high-income societies in recent years, only outdated studies are available for Italy. We aim to provide novel insights into the sexual behaviour and opinions of young Italians diachronically and through a gendered lens. Our analysis compares the results of two national samples of university students collected in 2000 and 2017. The sexual behaviour and opinions of young men and women seem to be converging in several respects. We observed a feminisation of male opinions and behaviour within couples, which is to say that men are more likely to experience first intercourse with a young woman of roughly the same age while in a stable relationship, and betray_or accept betrayal—with less frequency and willingness than in the past. Similarly, we found a masculinisation of female opinions and behaviour outside of stable relationships, for example, an increase in occasional partners, a net drop in the expectation that other women hold virgin status before marriage, and a doubling of the acceptance of casual sex. A few gender differences remain, especially concerning sexual double standards: young men and women are still subject to diverse rules guiding their sexual behaviour. Finally, acceptance of homosexuality has risen substantially_-particularly among women.

Keywords: Sexuality, Double standard, University students, Italy
\end{abstract}

\section{Introduction}

During the last 60 years, the sexual revolution-the process by which traditional codes of sexuality are challenged-has accelerated in many high-income countries (Laumann et al., 1994; Garton, 2004; Kontula, 2009; Barbagli et al., 2010). The sexual revolution is part of a larger change-a revolution in intimacy-that also includes other familyrelated behaviours, such as the spread of non-marital cohabitation, childbearing within cohabitation, and divorce (Ariès, 1960; Ariès and Duby, 1985-87; Lesthaeghe and van de Kaa, 1986; Giddens, 1990, 1992). The recent acceleration of the revolutionary process includes an increased acceptance of sexual behaviours for those outside of relationships, pornography use, premarital sex, increased stigma concerning partner betrayal in stable relationships, and a widespread acceptance of homosexuality. Women have been-to a greater extent than men-the protagonists in this step of the sexual revolution. Changes in sexual- and family-related behaviours have followed a similar

(c) The Author(s). 2020 Open Access This article is licensed under a Creative Commons Attribution 4.0 International License, which permits use, sharing, adaptation, distribution and reproduction in any medium or format, as long as you give appropriate credit to the original author(s) and the source, provide a link to the Creative Commons licence, and indicate if changes were made. The images or other third party material in this article are included in the article's Creative Commons licence, unless indicated otherwise in a credit line to the material. If material is not included in the article's Creative Commons licence and your intended use is not permitted by statutory regulation or exceeds the permitted use, you will need to obtain permission directly from the copyright holder. To view a copy of this licence, visit http://creativecommons.org/licenses/by/4.0/. 
clear-cut pattern of spatial diffusion. North-western European and Anglophonic countries were the first to follow this pattern. Countries in Eastern and Southern Europe and the wealthy countries of East Asia were among the last to follow this path, with other wealthier countries lying somewhere in between (Laumann et al., 1994; Bozon and Kontula, 1998; Wellings et al., 2006; Billari et al., 2007; World Health Organization [WHO], 2016).

Although the incidence of new family behaviour remains less evident in Italy than in Western European countries, Italy has experienced remarkable and varied changes regarding family-related behaviour in recent decades (De Rose and Strozza, 2015, pp. 7477; Pirani and Vignoli, 2016; Vignoli et al., 2018). The Italian Statistical Office (Istat) has studiously documented these trends. In 1993, 2 out of 100 couples were living in non-marital relationships, whereas, by 2015 , almost $20 \%$ of Italians had cohabited for at least part of their relationships. Since the 1990s, marriages in town halls (as opposed to churches) increased from less than 20 to almost 50\%. Marriages outside of the church are a clear indication of secularisation. The percentage of out-of-wedlock childbirth has tripled in the last 15 years, and data on legal separation rates are demonstrative of a clear trend in increased marital disruption over the last 20 years.

Whether and how these changes to public family life have been mirrored by changes to the sexual opinions and behaviour of Italians is unclear. Only partial, or outdated, studies are available for Italy, and the last representative national survey was held in 2006 (Dalla-Zuanna et al., 2005; Barbagli et al., 2010). We therefore aim to offer a timely overview of the opinions and behaviour of young Italian students regarding sexuality. As such, the present study asks the following specific questions:

1. What have been the main changes to the sexual behaviour of Italian students since the onset of the twenty-first century?

2. What differences can be detected between young men and women in terms of changing sexual behaviour?

3. Have the opinions of male and female Italian students regarding sex shifted over time?

Regarding those sexual behaviours which have changed most dramatically over the last seventeen years:

4. Has the influence of selected individual determinants varied over time?

To address these questions, we examined data from the Sexual and Emotional LiFe of Youths (SELFY) survey, which served to provide new information on the sexual and emotional behaviour of approximately 8000 young Italian university students. Moreover, SELFY replicated an identical survey held between 2000 and 2001 (henceforth listed as 2000) in which approximately 5000 students were surveyed using the same national sampling procedure and data collection technique-i.e. a self-completed questionnaire completed in the classroom during a lecture (Dalla-Zuanna and Crisafulli, 2004; Caltabiano et al., 2006; Billari et al., 2007).

Both the drawbacks and benefits of this kind of data should be addressed upfront. The main disadvantage is that such a survey is not representative of the entire 
population. Nonetheless, a sample of university students has many advantages-in particular, it allows for a large number of respondents who can complete a relatively long (40-min), though not complex, questionnaire. Within this group, high heterogeneity exists regarding both sexuality and affective behaviour, thereby making university students useful subjects for research (e.g. Keller, 1959; Pitts and Rahman, 2001; Billari et al., 2007; Hines, 2007; Weeden and Sabini, 2007; Stinson, 2010). The fact that the surveys for 2000 and 2017 are fully comparable is a crucial strength of our study.

\section{Literature review}

\section{Changes over time in sexual behaviours}

Several studies have addressed university students and their sexual behaviour with different focuses, including contraception (French and Holland, 2013; Walsh et al., 2014), casual sex (Olmstead et al., 2013), and the changes to timing and meaning of first intercourse (Sprecher, 2014). Relatively few studies have focused on the overall shifts in sexuality among university students (Lefkowitz et al., 2018), while none have focused on Italy.

The Italian context is characterised by a delay to the modernisation of sexual behaviour, at least in comparison to most other European countries.

"A distinctive feature of Italy is that the country experienced change [in sexual behaviour] many years later than central-northern Europe. The decline in ascetic and procreative sexual orientation and the affirmation of affective and hedonistic equivalents, a younger age at first intercourse, control of fertility, masturbation, premarital relationships, and oral sexual practices, all began later in Italy than in Sweden, Denmark, Great Britain, France, and Germany. (Barbagli et al., 2010, p. 305)"

This passage was written by the authors of the most complete study on Italian sexuality, which was conducted in 2006 (for further comparative research, see Caltabiano, 2006; Billari et al., 2007). Italy's gradual change in these matters is evident when comparing the various WHO surveys on early sexual intercourse in representative samples of young people living in middle- to high-income countries (WHO, 2016, pp. 179-190).

The delay to sexual changes in Italy could be said to be primarily due to the influence of the Catholic Church and the strength of intergenerational bonds. In Italy, the Catholic Church has retained a stronger and more marked presence in the socialisation of young people than in other European societies, for example, France or Spain (Caltabiano et al., 2006). Moreover, several studies have emphasised a link between strong family ties and family life in Italy (Dalla-Zuanna and Micheli, 2004; Rosina and Fraboni, 2004; Schröder, 2008). Parents tend to discourage non-normative behaviour in their offspring, and even adult children feel great parental pressure when making their own choices (Rosina and Fraboni, 2004; Vignoli and Salvini, 2014). In the gradual spread of non-marital cohabitation, the influence of the older generation has proven to be crucial (see Belletti et al., 2007).

Nevertheless, the sexual revolution has indeed reached Italy (Caltabiano, 2006; Billari et al., 2007). Even among women, sexuality has become increasingly disconnected from reproduction, whereas sexual pleasure is playing an ever-greater and central role for men and women, whether single individuals or couples (Barbagli et al., 2010). Furthermore, 
public discourse around sexuality has altered profoundly, and legislation has become less rigid (e.g. civil unions between same-sex partners were legalised in Italy in 2016).

As such, our first question is the following: What have been the main changes to the sexual behaviour of Italian students since the onset of the twenty-first century?

\section{Gender differences}

In many aspects of life, men and women's behaviour in the public and private sphere has converged (which is the case also in Italy). In particular, women are more present in the labour market (OECD data), whereas men are increasingly involved in care work (Dotti Sani and Treas, 2016). However, the literature indicates that these processes are slower in Italy than in other Western countries and that the traditional division of roles is still strong in Italian society (Guetto et al., 2015). The evolution of gender differences in youth sexuality is, however, largely unexplored. Studies pertaining to other countries have indicated that, in some respects, women have tended to adopt traditionally 'masculine' behaviour, especially in the search for sexual gratification for its own sake (through masturbation or casual sex; e.g. Kontula, 2009). Conversely, men have been exhibiting traditionally 'feminine' behaviour, not least the repudiation of betrayal (e.g. Mercer et al., 2013). Moreover, new gender differences have emerged, most notably in the opinions and behaviour concerning homosexuality (see Kontula, 2009, pp. 65-69; Mercer et al., 2013).

The information available for Italy about past sexual behaviour is indicative of a gender convergence in recent decades (e.g. in the timing of the first sexual experience; Barbagli et al., 2010). However, strongly traditional attitudes towards gender roles-which still play an important role in Italian society (Lomazzi, 2016)-may well hinder this transition or place it on a characteristically Italian path. Therefore, we are interested in understanding whether Italian men and women have been converging in terms of sexual behaviour and, if so, in explaining any apparent patterns. In particular, we seek to examine whether there is a 'masculinisation' of behaviour, that is, whether females increasingly resemble males (a pattern typical of countries with high levels of gender equality) and whether there is a greater occurrence of 'feminisation' (i.e. young men coming to resemble the behaviour of their female companions).

Our second research question is therefore the following: What differences can be detected between young men and women in terms of changing sexual behaviour?

\section{Opinions towards sexuality and the sexual double standard}

Analysing sexuality also means examining the behaviour and opinions surrounding sex. Behaviour and opinions are typically co-dependent-especially in an issue as sensitive as sexuality. A review of gender attitudes towards sexuality has provided several important indications about the direction that opinions have taken elsewhere (Petersen and Hyde, 2011). Male-female openness has converged over time. Change has been occurring in several areas connected with sexuality, such as casual sex and the acceptance of premarital sex (Wells and Twenge, 2005). Moreover, students (particularly female students) tend to be much more critical of extramarital sex than adults who have already concluded their educational career (Petersen and Hyde, 2011). Regarding homosexuality, men tend to be less accepting than women. This discrepancy has 
remained consistent over time and is conspicuous among university students (Petersen and Hyde, 2010).

Sexual double standards play a role regarding these opinions. By 'double standard', we mean the different behavioural rules that men and women are subjected to (Crawford and Popp, 2003). More specifically, the sexual double standard 'consists of judging heterosexual men and women differently for the same sexual behaviour' (Gómez Berrocal et al., 2019, p. 1664). The standards of sexual conduct differ for men and women and are based on sexual scripts that are 'socially constructed cognitive schema that define normative sexual behaviours and inform individual actions in sexual situations' (Simon and Gagnon, 1984, 1986, 2003, in Kreager et al., 2016, p. 378). Women are judged more critically (and typically negatively) than men for the same sexual behaviours, and their sexual freedom is more restricted (Zaikman and Marks, 2017). Typically, in the past, premarital sex and sex outside of wedlock were considered more acceptable for men. These types of behaviours were not only discouraged for women but were also a source of social stigma (first results in Reiss, 1956; see also Marks and Fraley, 2006; Bordini and Sperb, 2013).

The debate concerning sexual double standards is still ongoing and continues to attract the attention of researchers conducting both quantitative and qualitative research (Crawford and Popp, 2003; England and Bearak, 2014; Kreager et al., 2016). The majority of international literature addresses the university-aged population (Bradshaw et al., 2010; Allison and Risman, 2013; Conley et al., 2013). Little is known, however, of Italian university students. To the best of our knowledge, the only available study for Italy that uses data from the year 2000 demonstrated that different norms exist for male and female students in terms of first sexual intercourse (Billari and Mencarini, 2004). A recent qualitative study has confirmed the persistence of double standards among Italian men (Ferrero Camoletto, 2014). New insights can facilitate our understanding of whether opinions concerning sexuality and sexual behaviour are changing, and whether the sexual double standard continues to persist among Italian university students.

Consequently, our third question is the following: Have the opinions of male and female Italian students regarding sex shifted over time?

\section{Factors affecting changing sexual behaviours}

The final research question concerns the context in which changes to the sexuality of young Italian students emerge. As with other aspects of reproductive and family behaviour, new sexual behaviour does not necessarily spread homogeneously but instead differs according to contextual and individual circumstances. We thus believe it is necessary to consider several potential determinants of sexual behaviour and explore their eventual change in terms of relevance and magnitude: residence during adolescence, parental socioeconomic conditions, education received in the family (permissive or repressive), secondary school experience (tracks and marks), personal and parental religiosity, and the presence (or absence) of health problems.

Only a selection of the sexual behaviours for which we collected data will be analysed. In fact, we scrutinised the changing determinants of a selected pool of sexual behaviour which past research has already shown to be crucial and, according to our data, changed more significantly over time than others. These are the number of males watching 
pornography (Goodson et al., 2001; Braitwaite et al., 2015; for Italy, Romito and Beltramini, 2011; Cuccì et al., 2017; Scarcelli and Stella, 2019), the number of females who have had homosexual experiences (Goode and Haber, 1977; Kuperberg and Walker, 2018), the number of males betraying their partner (Allen and Baucom, 2006; McAnulty and Brineman, 2007; Norona et al., 2015), and having three or more sexual partners for females (Wiederman, 1997; Brown and Sinclair, 1999; Eisenberg, 2001; Zelin et al., 2015; Mitchell et al., 2019). As each of these behaviour has its own specificity, it is not possible to discuss in-depth every main determinant of these four sexual behaviours in a single study. However, we believe that the general overview offered by this paper can contribute to future targeted research.

Our last research question is the following: Has the influence of selected individual determinants varied over time?

\section{Data and methods}

This study is based on SELFY, a survey coordinated by researchers from the universities of Florence, Messina, and Padua. The survey was conducted in the first half of 2017 in 28 Italian universities to provide an updated portrayal of sexual and affective opinions and behaviour among Italian university students. The SELFY survey was almost identical to one conducted 17 years previously. In 2000 and 2017, 4998 and 8094 students were surveyed, respectively. All respondents were attending Italian undergraduate courses in economics and statistics.

The SELFY data allows a comparison between 2000 and 2017 for four reasons. First, both surveys used the same questionnaire. Second, we were able to use the same criteria to determine our sample. Third, the size of both samples allows for a meaningful comparison, and fourth, unit-nonresponses were virtually non-existent in both surveys. However, it should be noted that our samples are not representative of young Italians as a whole. The sexuality of our sample of university students enrolled in economics and statistics courses appears to be more delayed, and less intense, than that of their less-educated peers. Moreover, their sexuality is aligned with (or, again, slightly more delayed and less intense than) that of university students enrolled in other courses. See the Appendix for a detailed description of the survey, as well as a discussion on the representativeness of SELFY data compared with other surveys.

The study's analytical strategy consists of determining the incidence of 28 forms of behaviour or opinions by reporting both surveys' proportion of positive answers to the response variables for students of both sexes. We divided the 28 items into 3 groups. The first group includes sexual behaviour potentially experienced by all students: first sexual intercourse before their 16th/18th (male/female) birthday, first sexual non complete experience before their 16th birthday, first couple relationship before their 16th birthday, frequently speaking about sex with friends, regular watching of pornography, and at least one homosexual experience.

The second group consists of the sexual behaviours of non-virgin students (3086 in 2000 and 6085 in 2017): contraception use in first sexual intercourse, occasional partner at the first sexual intercourse, only one sexual partner in life, three or more sexual partners in life, casual sex at least once, betrayal of a partner, frequency of sex (once a month or less vs. two to three times a week), sexual experiences at risk of HIV, and having contracted a sexually transmitted disease (STD). 
The third group contains sexual opinions concerning the following: very early sexual intercourse, betrayal during a relationship, casual sex, maintaining virginity until marriage, and homosexual intercourse.

Stratifying the sample by gender enabled us to reflect on changing gender differences. These proportions were post-stratified so as to make them more representative of young university students (with an average age of 20) studying economics and statistics at the national level (see the Appendix). All of the documented indicators, such as the median age for certain sexual events, were weighted in the same manner. The median ages for first sexual intercourse in 2000 and 2017 were also calculated (separately for men and women) at the macro-region level.

To explore temporal and gender differences, we estimated a set of logistic models on the merged databases from the two surveys. Our key explanatory variable in each logistic model was the combination of gender $\times$ time: men in 2000 (reference), men in 2017, women in 2000, and women in 2017. For each odds ratio (OR) of the gender $\times$ time variable, we listed the confidence interval $(p=.05)$. We employed a specific format to mark the statistical differences, emphasising in the same model the differences between year and gender. The OR for 2017 has been written in bold when the confidence interval did not include 1 (for men) or did not overlap with the 2000 confidence interval (for women). The OR for women has been marked with an asterisk when the confidence interval did not include 1 (for 2000) or did not overlap with the confidence interval for men (for 2017).

Comparisons between ORs based on two confidence intervals provide more conservative results than those obtained by modifying the baseline category. Simply put, when the confidence intervals of two ORs do not overlap, we can be confident of a statistically significant difference between them if either of the two modalities of the comparison object is set as a baseline. These 28 logistic models also each include the same 17 covariates that control for possible confounding factors (see the Appendix). The complete set of logistic models is available upon request.

\section{Results}

We present our results over four sub-sections. We address the first and second research questions in the "Sexual behaviour of the students" and "The characteristics of the sexual behaviour of non-virgins" sections. We first offer a comparison between time and gender for the sexual behaviour of all students before turning our focus to nonvirgin students. We address the third research question in the "Opinions on sexuality and the sexual double standards" section. We also scrutinise Italian students' opinions regarding sexuality while highlighting sexual double standards. Finally, we address the fourth research question in the "Changing influence of contextual and individual characteristics on sexual behaviour" section.

\section{Sexual behaviour of the students}

Between 2000 and 2017, the median age ${ }^{1}$ at first sexual intercourse decreased by 1 year for young men and 1.2 years for young women (Table 1). In the past, men were more likely to experience their sexual debut earlier than women. However, among the cohort

\footnotetext{
${ }^{1}$ The median considers censored cases (respondents who had not experienced a sexual debut by the time of interview) and avoids a downward estimation bias affecting the mean age.
} 
Table 1 Median age at certain behaviours by gender, 2000-2017

\begin{tabular}{|c|c|c|c|c|}
\hline \multirow[t]{2}{*}{ Year } & \multicolumn{2}{|l|}{ Males } & \multicolumn{2}{|c|}{ Females } \\
\hline & 2000 & 2017 & 2000 & 2017 \\
\hline First sexual intercourse & 18.9 & 17.9 & 19.2 & 18.0 \\
\hline First sexual non complete experience & 15.5 & 15.5 & 16.5 & 16.5 \\
\hline Entry into the first couple relationship & 16.5 & 16.2 & 15.8 & 15.8 \\
\hline
\end{tabular}

Note: For the first intercourse and the first couple relationship, participants were asked to recall the month and year. The age at these two events is calculated as the distance from the month/year of birth. In contrast, for the first sexual non complete experience, participants were only asked to recall the age (in years)

born at the end of the twentieth century, female students have converged with their male counterparts. Sexual initiation now seemingly occurs at the same age for both genders. The closed gender gap in the age at first sexual intercourse is due to the rapid change in young women's sexual behaviour in the south of the country. In some northern and central regions of the peninsula, students were likely to already be having sex at similar ages at the beginning of the twenty-first century (Table 2). The ages of first sexual non complete experience and entry into the first relationship, however, did not change significantly (Table 1 ).

Table 3 illustrates the sexual behaviours of all surveyed students by gender and time. The ORs for men and women show a statistically significant difference in 2017 as compared to 2000 (transcribed in bold). The asterisk indicates statistically significant differences between male and female students. Even when controlling for several confounding factors, the age at first sexual intercourse significantly decreased for both males and females between 2000 and 2017. We observed this while bearing in mind the increasing probability of first intercourse occurring before the age of 18. In 2017, we also noted an increase in very early intercourse (before the 16th birthday, as defined by the WHO, 2016; and for Italian university students in Gabrielli and Borgoni, 2007) for

Table 2 Median age at first sexual intercourse by region and gender, 2000-2017

\begin{tabular}{|c|c|c|c|c|}
\hline & \multicolumn{2}{|l|}{ Males } & \multicolumn{2}{|c|}{ Females } \\
\hline & 2000 & 2017 & 2000 & 2017 \\
\hline \multicolumn{5}{|l|}{ North } \\
\hline Piedmont, Liguria, Aosta Valley & 18.7 & 17.8 & 19.3 & 17.6 \\
\hline Lombardy & 19.2 & 18.8 & 18.8 & 18.4 \\
\hline Veneto, Trentino-Alto Adige, Friuli Venezia Giulia & 19.2 & 18.3 & 19.4 & 18.3 \\
\hline \multicolumn{5}{|l|}{ Centre } \\
\hline Tuscany & 18.2 & 17.7 & 18.4 & 17.3 \\
\hline Emilia-Romagna, The Marches, Umbria & 18.8 & 18.3 & 18.1 & 18.0 \\
\hline Lazio, Abruzzo, Molise & 19.5 & 17.6 & 19.8 & 17.7 \\
\hline \multicolumn{5}{|l|}{ South } \\
\hline Campania & 19.4 & 17.3 & 19.8 & 18.3 \\
\hline Puglia, Basilicata & 18.8 & 17.9 & 19.2 & 18.0 \\
\hline Calabria & 17.8 & 17.8 & 21.0 & 18.1 \\
\hline \multicolumn{5}{|l|}{ Islands } \\
\hline Sicily & 18.5 & 17.6 & 20.4 & 17.7 \\
\hline Sardinia & 18.3 & 17.9 & 18.8 & 17.3 \\
\hline
\end{tabular}

Note: Some regions are combined due to small sample sizes 
Table 3 Odds ratio and confidence interval $(p=0.05)$ for certain sexual behaviours by gender and time (2000-2017). Sexual behaviour of all surveyed students

\begin{tabular}{ccccc}
\hline & $\%$ & Value & Min & Max \\
\hline First sexual intercourse before 18th birthday & & & \\
M 2000 & 35.8 & 1 & & 1.753 \\
M 2017 & 50.1 & $\mathbf{1 . 5 4 4}$ & 0.780 & 1.047 \\
F 2000 & 33.1 & 0.904 & 1.560 & 2.058 \\
F 2017 & 49.9 & $\mathbf{1 . 7 9 2}$ &
\end{tabular}

First sexual intercourse before 16th birthday

$\begin{array}{lllll}\text { M } 2000 & 12.5 & 1 & & \\ \text { M } 2017 & 18.6 & \mathbf{1 . 4 2 9} & 1.190 & 1.716 \\ \text { F } 2000 & 9.1 & 0.687^{*} & 0.546 & 0.864 \\ \text { F } 2017 & 18.9 & \mathbf{1 . 8 7 2} & 1.547 & 2.265\end{array}$

First non complete experience before 16th birthday

$\begin{array}{lllll}\text { M } 2000 & 52.5 & 1 & & \\ \text { M } 2017 & 53.2 & 0.819 & 0.719 & 0.932 \\ \text { F } 2000 & 42.1 & 0.680^{*} & 0.591 & 0.783 \\ \text { F } 2017 & 46.3 & 0.741 & 0.647 & 0.849\end{array}$

First couple relationship before 16th birthday

$\begin{array}{lllll}\text { M } 2000 & 44.8 & 1 & & \\ \text { M } 2017 & 47.5 & 1.132 & 0.988 & 1.296 \\ \text { F } 2000 & 51.6 & 1.415^{*} & 1.224 & 1.635 \\ \text { F } 2017 & 52.6 & 1.605^{*} & 1.394 & 1.850\end{array}$

Often watching porn on the web during the last year

$\begin{array}{lllll}\text { M } 2000 & 10.4 & 1 & & \\ \text { M } 2017 & 39.5 & \mathbf{5 . 2 9 8} & 4.516 & 6.215 \\ \text { F } 2000 & 0.4 & 0.071^{*} & 0.059 & 0.085 \\ \text { F } 2017 & 2.8 & \mathbf{0 . 1 5 9}^{*} & 0.137 & 0.185\end{array}$

Often speaking about sex with a friend at age 16-18

$\begin{array}{lllll}\text { M } 2000 & 67.1 & 1 & & \\ \text { M } 2017 & 67.0 & 0.936 & 0.818 & 1.071 \\ \text { F } 2000 & 48.3 & 0.529^{*} & 0.459 & 0.610 \\ \text { F } 2017 & 46.3 & 0.402^{*} & 0.350 & 0.462\end{array}$

At least once homosexual experience

$\begin{array}{lllll}\text { M } 2000 & 6.4 & 1 & & \\ \text { M } 2017 & 7.2 & 1.033 & 0.799 & 1.337 \\ \text { F } 2000 & 4.3 & 0.727^{*} & 0.537 & 0.985 \\ \text { F } 2017 & 14.9 & \mathbf{2 . 3 2 7 ^ { * }} & 1.811 & 2.989\end{array}$

Note: Percentages (in italics) and odds ratios for gender $\times$ time variable $(M e n 2000=1)$. Seven logistic models fitted on the merged 2000 and 2017 datasets.

The list of the control covariates and their distributions is reported in the Appendix Bold indicates the odds ratios for 2017 are significantly different from the odds ratios for 2000 for both men and women For both years the asterisk means that the odd ratio for women is significantly different from that for men

$20 \%$ of students of both genders. The period change is irrelevant for the timing of the following categories: first sexual non complete experience, first couple relationship, and talking about sex with friends (between the ages of 16 and 18). 
Regarding the use of web pornography, both gender difference and time variation were found to be relevant. Intensive pornography use is essentially a male matter, with $40 \%$ of students in 2017 admitting to visiting pornography sites often or very often-a figure almost quadruple that of 2000 (when access to pornographic websites was more difficult). For female students, intensive web pornography use also increased over time but, even in 2017, only $3 \%$ of the sample admitted to being intensive users.

We observed a type of 'gender revolution' for homosexual experiences. In 2000, homosexual experiences were more frequent among males (yet it should be noted that the difference was statistically insignificant). In 2017, by contrast, twice as many women as men claimed to have had homosexual experiences. From an additional analysis, we found a higher incidence among females for two other dimensions of homosexuality (which were only surveyed in 2017). Non-heterosexual identity was slightly higher among females: $3.7 \%$ of females (0.8\% lesbian and $2.9 \%$ bisexual), compared to $3 \%$ of males (1.3\% gay and $1.7 \%$ bisexual), declared they were nonheterosexual. Additionally, $10.7 \%$ of females (compared to $5.7 \%$ of males) admitted experiencing sexual attraction to people of the same sex. Moreover, $19.8 \%$ of women responded positively to at least one of the three variables mentioned above, thus indicating a tendency towards homosexuality or bisexuality. The same was true for $10.1 \%$ of males.

\section{The characteristics of the sexual behaviour of non-virgins}

Table 4 illustrates that the use of modern contraception at the first intercourse among students increased to almost 80\% in 2017 (71.2\% condoms, $7.4 \%$ pills, and $0.4 \%$ intrauterine devices [IUDs]). In 2017, the proportion of students having their first sexual intercourse with an occasional partner differed by gender $(29.4 \%$ among men vs. $11.8 \%$ among women). Notably, this difference is smaller than that found in 2000, predominantly due to a reduction in the number of young men having first intercourse with an unknown partner. Consistently, additional analysis shows that the proportion of young adults who declared having had first sexual intercourse with a person of the same age increased from 56.3 to $67.5 \%$ among males and from 68.1 to $76.6 \%$ among females. Among students born at the end of the 1990s, first sexual intercourse-even if it occurred at an earlier age compared to students born in the early 1980s-was often experienced inside a stable relationship and with a greater awareness of contraception.

As a consequence of the the 1-year decrease in age at first intercourse, the number of partners increased for both genders. In 2017, more males than females had three or more partners, and more women than men had just one sexual partner. However, the gender gap significantly narrowed, as the number of females stating that they had occasional partners at least once doubled when compared to 2000. This number was still lower than for males, but the gender gap is closing. The change is not due to infidelity in stable emotional relationships but rather to increasing sexual encounters among single individuals. The proportion of young male students who claimed to have betrayed a partner decreased between 2000 and 2017.

The frequency of sexual intercourse is higher for females than for males, with certain important differences being found between 2000 and 2017 (e.g. the model 'sex 2-3 
Table 4 Odds ratio and confidence interval $(p=0.05)$ for certain sexual behaviours by gender and time (2000-2017). The sexual behaviour of surveyed students who had already had sexual intercourse

\begin{tabular}{cllll}
\hline & $\%$ & Value & Min & Max \\
\hline Condom, pill or IUD at first sexual intercourse & & & \\
M 2000 & 74.6 & 1 & 1.001 & 1.435 \\
M 2017 & 79.9 & $\mathbf{1 . 1 9 9}$ & 0.561 & 0.832 \\
F 2000 & 65.2 & $0.684^{*}$ & 0.911 & 1.331 \\
F 2017 & 78.5 & $\mathbf{1 . 1 0 1}$ & & \\
Occasional partner at first sexual intercourse & & & \\
M 2000 & 35.5 & 1 & 0.615 & 0.850 \\
M 2017 & 29.4 & $\mathbf{0 . 7 2 3}$ & 0.169 & 0.269 \\
F 2000 & 9.1 & $0.213^{*}$ & 0.214 & 0.317 \\
F 2017 & 11.8 & $0.260^{*}$ &
\end{tabular}

One sexual partner (until the survey)

$\begin{array}{ll}\text { M } 2000 & 38.7 \\ \text { M } 2017 & 32.2 \\ \text { F } 2000 & 58.2 \\ \text { F } 2017 & 42.3\end{array}$

1

$\begin{array}{lll}0.954 & 0.808 & 1.126\end{array}$

$2.122^{*} \quad 1.769$

F 2017

1.294

1.091

1.536

Three sexual partners or more (until the survey)

$\begin{array}{ll}\text { M } 2000 & 30.7 \\ \text { M } 2017 & 37.3 \\ \text { F } 2000 & 12.9 \\ \text { F } 2017 & 23.8\end{array}$

\section{1}

1.187

$0.406^{*}$

$0.750^{*}$

Casual sex (at least once)

$\begin{array}{ll}\text { M } 2000 & 47.4 \\ \text { M } 2017 & 52.7 \\ \text { F } 2000 & 14.9 \\ \text { F } 2017 & 27.6\end{array}$

Betrayed the partner (at least once)

$\begin{array}{ll}\text { M } 2000 & 27.2 \\ \text { M } 2017 & 22.7 \\ \text { F } 2000 & 12.1 \\ \text { F } 2017 & 12.7\end{array}$

Sex once a month or less (in previous 3 months)

$\begin{array}{ll}\text { M } 2000 & 43.8 \\ \text { M } 2017 & 44.8 \\ \text { F } 2000 & 29.4 \\ \text { F } 2017 & 30.9\end{array}$

Sex 2-3 times a week or more (in previous 3 months)

$\begin{array}{lllll}\text { M } 2000 & 27.6 & 1 & & \\ \text { M } 2017 & 25.9 & 0.892 & 0.756 & 1.052 \\ \text { F } 2000 & 30.7 & 1.230^{*} & 1.020 & 1.482 \\ \text { F } 2017 & 34.0 & 1.267^{*} & 1.066 & 1.507\end{array}$

Sexual experience at risk of HIV (at least once)

M $2000 \quad 32.1 \quad 1$

M 2017

37.8

0.495

0.892

$\begin{array}{lll}0.998 & 0.858 & 1.163 \\ 0.171^{*} & 0.139 & 0.211 \\ \mathbf{0 . 3 7 1}^{*} & 0.313 & 0.440\end{array}$

$\begin{array}{lll}\mathbf{0 . 7 8 4} & 0.658 & 0.935\end{array}$

$\begin{array}{lll}0.412^{*} & 0.327 & 0.519\end{array}$

$\begin{array}{lll}0.389^{*} & 0.316 & 0.479\end{array}$

$\begin{array}{lll}1.036 & 0.892 & 1.203\end{array}$

$\begin{array}{lll}0.496^{*} & 0.416 & 0.592\end{array}$

$\begin{array}{lll}0.593^{*} & 0.504 & 0.697\end{array}$ 
Table 4 Odds ratio and confidence interval $(p=0.05)$ for certain sexual behaviours by gender and time (2000-2017). The sexual behaviour of surveyed students who had already had sexual intercourse (Continued)

\begin{tabular}{ccccc}
\hline & $\%$ & Value & Min & Max \\
\hline F 2000 & 24.2 & $0.738^{*}$ & 0.634 & 0.860 \\
F 2017 & 34.3 & $\mathbf{1 . 0 0 0}$ & 0.867 & 1.154 \\
Had a sexually transmitted disease (at least once) & & & \\
M 2000 & 4.2 & 1 & & 1.597 \\
M 2017 & 7.0 & 1.206 & 0.911 & 2.246 \\
F 2000 & 6.3 & $1.663^{*}$ & 1.231 & 3.038 \\
F 2017 & 11.6 & $2.295^{*}$ & 1.734 & \\
Casual sex without using & condom (at least once) & & & \\
M 2000 & 26.0 & 1 & $\mathbf{1 . 8 8 9}$ \\
M 2017 & 39.1 & $\mathbf{1 . 6 0 0}$ & $\mathbf{1 . 3 5 6}$ & 0.843 \\
F 2000 & 18.8 & $0.686^{*}$ & 0.559 & 1.504 \\
F 2017 & 32.5 & $\mathbf{1 . 2 5 7}$ & 1.051 & \\
\hline
\end{tabular}

Note: Percentages (in italics) and odds ratios for gender $\times$ time variable (Men2000 $=1$ ): eleven logistic models fitted on the merged 2000 and 2017 datasets. The list of the control covariates and their distributions is reported in the Appendix. Bold indicates the odds ratios for 2017 are significantly different to the odds ratios for 2000 for both men and women For both years the asterisk means that the odd ratio for women is significantly different from that for men

times a week'). This could be explained by more young women (64.5\% in 2017) than young men $(47.3 \%)$ being engaged in a relationship with a non-virgin at the time of the survey, and sexual activity tends to be significantly more intense than for a single person in this circumstance. For example, in 2017, the proportion of non-virgins having sexual intercourse at least twice a week was $9 \%$ among single males, $11.1 \%$ among single females, $45.6 \%$ among males in a relationship, and $47.7 \%$ among females in a relationship. As expected, being in a couple is a prerequisite for having frequent sexual intercourse, and it aids both the intensity of, and satisfaction with, sex. Additional analysis revealed that, among non-virgins in 2017, the proportions of students 'quite' or 'very satisfied' with their current sex lives were 39.5\% among single men, $40.2 \%$ among single women, $91.3 \%$ among men in a couple, and $92.9 \%$ among women in a couple.

We concluded our exploration of the sex lives of Italian students by turning our attention to sexual health risks. Our findings show a disconcerting increase in sexual relations at a high risk of HIV, incidence of sexually transmitted diseases, and unprotected casual sex. An increase between 2000 and 2017 is visible and significant for both genders.

\section{Opinions on sexuality and the sexual double standards}

Table 5 displays the opinions on sexual behaviour held by all surveyed students by gender and time. In the first two decades of the new millennium, the proportions of males and (especially) females who accept early sex, casual single sex, and pre-nuptial and homosexual experiences have increased. The doubling of the numbers of those who approve of homosexual experiences is perhaps the most salient result. Only when male students were asked about tolerating affairs during stable intimate relationships did their tolerance decrease. During the studied 17 years, decreases occurred depending on who committed the act of betrayal. For female respondents, tolerance was very low in both surveys. 
Table 5 Opinions, odds ratio and confidence interval $(p=0.05)$ the sexual behaviour of all the students surveyed (2000-2017)

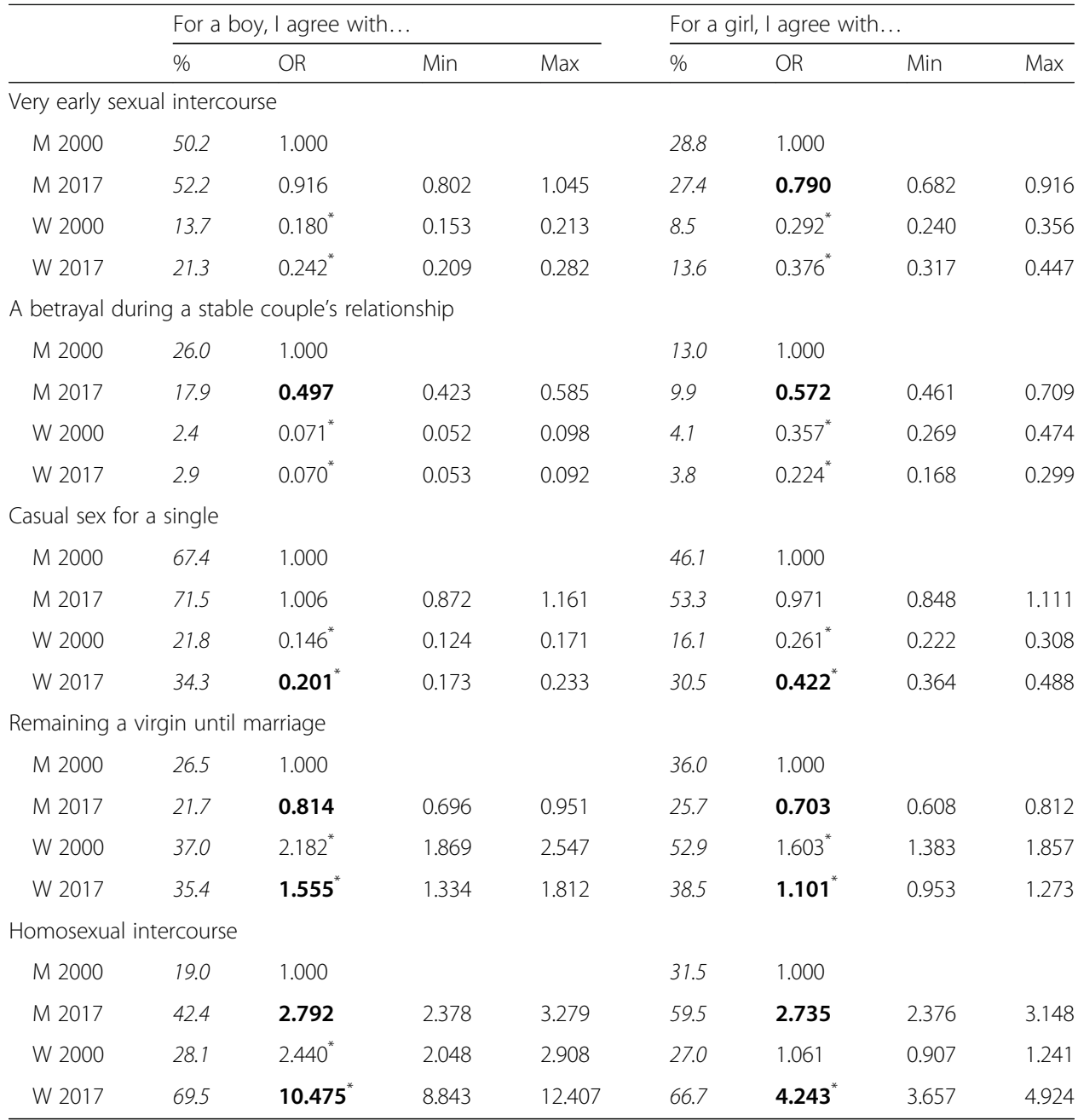

Note: Percentages of the sum of 'agree' and 'strongly agree' (in italics) and the odds ratios for the variable gender $\times$ time (Men2000 = 1): ten logistic models fitted on the merged 2000 and 2017 datasets. The list of the control covariates and their distributions is reported in the Appendix

Bold indicates the odds ratios for 2017 are significantly different from the odds ratios for 2000 for both men and women For both years the asterisk means that the odd ratio for women is significantly different from that for men

Regarding gender differences in opinions, the confidence intervals for men did not overlap with those for women, indicating a confirmation in 2017 of the gender differences found in 2000. Regardless, compared to 2000, the distance between men and women decreased across the board in 2017, suggesting that while males and females still have diverse opinions, these have become less so since 2000. For example, male students' opinions on casual sex did not change between 2000 and 2017 (two thirds approved of casual sex experienced by males, whereas only half approved of casual sex experienced by females). The proportion of tolerant females, however, increased significantly from 22 to $34 \%$ for males and from 16 to $31 \%$ for females.

While women were found to be generally less tolerant than men, the opposite is true concerning opinions on homosexual behaviour. Female students were more tolerant of homosexual intimacy than male students-a difference especially striking for male homosexuality. In any event, for both genders, the number of those tolerating 
homosexuality more than doubled between 2000 and 2017. The absolute increase in tolerance was greater among women, leading to a greater distance between genders.

To gain insights into sexual double standards, we compared two columns of frequencies using the differences between the acceptance of male and female behaviour both by gender and year (Fig. 1). We can therefore see the difference between the tolerance of men towards several sexual behaviours in 2000 and 2017 with respect to the tolerance of women. Should the difference between the two frequencies on the same line be at zero (or close to zero), then no sexual double standard could be detected. In both years, double standards were more pronounced among men than among women. Figures above zero indicate that the behaviour is more likely to be accepted for men than for women. Double standards persisted in 2017, although these could be said to have generally attenuated. Examining opinions towards casual sex for single individuals, in 2000, 67\% of men were tolerant towards males and $46 \%$ were tolerant for females-a difference of more than 20 percentage points. While the difference remained in 2017, it was slightly less pronounced ( $71 \%$ for males and $53 \%$ for females). Women were far less likely to have sexual double standards. The difference between their opinions on male and female behaviour was 6 percentage points in 2000 ( $22 \%$ accepted this behaviour for males and $16 \%$ for females), but only 3 points in 2017 (34\% for males and 31\% for females).

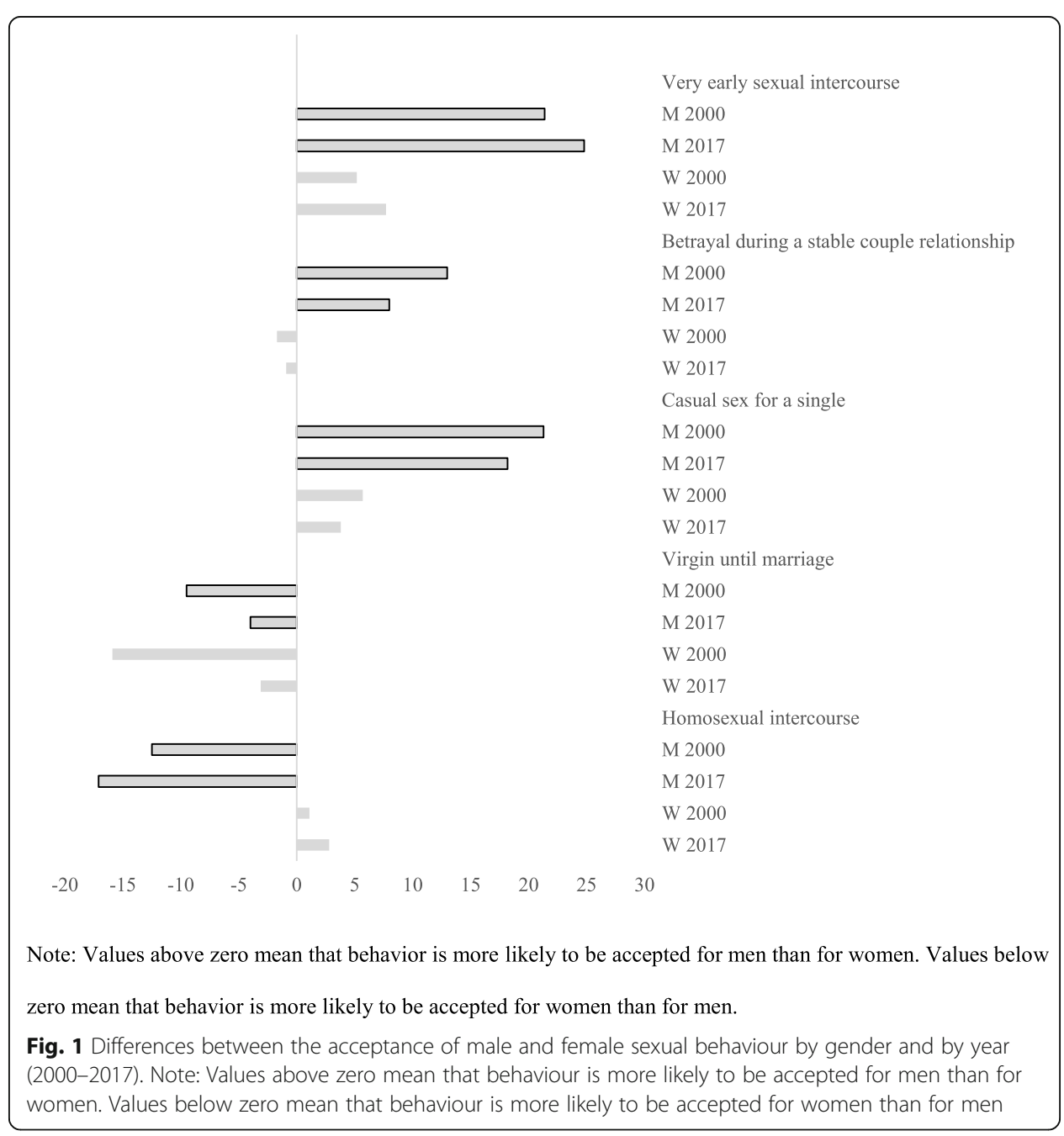


Even more marked were the differences between men and women regarding double standards on homosexuality. We found no double standards among females in either 2000 or 2017. Among males, however, these were more pronounced in 2017 than in 2000 , with a greater tolerance for female homosexuality. Overall, these results on sexual double standards illustrate that the opinions of men and women have grown closer over time; however, there is still a great distance to travel before we reach complete gender equality in opinions towards sexuality.

\section{Changing influence of contextual and individual characteristics on sexual behaviour}

We focused on the changing determinants of a selected number of sexual behaviours, namely those that experience a more significant change over time: the number of males watching pornography, the number of females who have had homosexual experiences, the betrayal of the partner for males, and having three or more sexual partners for females. While we were not interested in the effect of each single covariate, we focused our attention on exploring whether the relevance of certain covariates changed between 2000 and 2017 (Table 6; complete models in Tables A3a and A3b of the Appendix).

Regarding the number of males watching pornography, our analyses indicated that the 'reaction to parental rule' variable became significant in 2017. Body mass index (BMI) and having at least three health problems were significant in 2000, but not in 2017. Among the variables that remained significant in both surveys, higher levels of religiosity the number of students affirming to watch pornography often. In contrast, having parents who often attend mass increased the likelihood of watching pornography in 2000. The same was found in 2017, but only if it was the mother who attended mass.

Regarding the number of females who have had homosexual experiences, parental education, the father's social class, and the type of school were no longer significant in 2017. Nonetheless, the reaction to parental rules during teenage years and, in particular, disagreeing or negotiating with parents, and having parental permission to stay out late on Saturdays became significant in 2017. Note that our models only point out associations, and they have limited power to inform us about causal relationships.

Regarding the betrayal of the partner for males, the associated covariates appeared relatively stable over time. The variable determining whether the mother was in active employment was significant in both years, but having a working mother was associated with having experienced betrayal only in 2017. Talking with parents about affective life between the ages of 14-15 was positively associated with betrayal in both 2000 and 2017. In contrast, the reaction to parental rules during the participants' teenage years was positively associated with past betrayal only for those who denied parental rule, while it was positive for the recent cohort among those who negotiated the rules. Moreover, the variable concerning the participants' high school grades was significant for both years: higher grades corresponded with a lower chance to betray. However, for both years, the only category to remain significant and negative included students with good grades at both junior and senior high school levels. Finally, in both survey years, those who attended vocational schools were more likely to betray their partners than those in high school.

Regarding females with three or more sexual partners, we found that dissatisfaction with one's own physical appearance during one's teenage years was the only factor 
Table 6 Significant variables included in the models about watching porn (males), homosexual experiences (females), betrayal of the partner (males), three sexual partners or more (females): 2000-2017

\begin{tabular}{|c|c|c|c|c|c|c|c|c|}
\hline & \multirow{2}{*}{\multicolumn{2}{|c|}{$\begin{array}{l}\text { Watching } \\
\text { porn } \\
\text { Males }\end{array}$}} & \multirow{2}{*}{\multicolumn{2}{|c|}{$\begin{array}{l}\begin{array}{l}\text { Homosexual } \\
\text { experiences }\end{array} \\
\text { Females }\end{array}$}} & \multirow{2}{*}{\multicolumn{2}{|c|}{$\begin{array}{l}\begin{array}{l}\text { Betrayal of } \\
\text { the partner }\end{array} \\
\text { Males }\end{array}$}} & \multirow{2}{*}{\multicolumn{2}{|c|}{$\begin{array}{l}\text { Three sexual partners } \\
\text { or more } \\
\text { Females }\end{array}$}} \\
\hline & & & & & & & & \\
\hline & 2000 & 2017 & 2000 & 2017 & 2000 & 2017 & 2000 & 2017 \\
\hline Age at survey & & & & & sign. & sign. & sign. & sign. \\
\hline Area of residence during teens & sign. & sign. & sign. & sign. & sign. & sign. & & sign. \\
\hline \multicolumn{9}{|l|}{$\begin{array}{l}\text { Population size of the municipality of residence } \\
\text { during teens }\end{array}$} \\
\hline Parents' education & & & sign. & & & & sign. & sign. \\
\hline $\begin{array}{l}\text { Mother was working when the respondent was 14- } \\
15\end{array}$ & & & & & sign. & sign. & & sign. \\
\hline Social class of the father & sign. & sign. & sign. & & sign. & & & \\
\hline $\begin{array}{l}\text { Talked with parents about his/her affective life when } \\
\text { 14-15 }\end{array}$ & & & & & sign. & sign. & sign. & sign. \\
\hline Parents divorced before the respondent was 16 & & & & & & & & sign. \\
\hline Reaction to parents' rules during teens & & sign. & & sign. & sign. & sign. & & sign. \\
\hline $\begin{array}{l}\text { Parents allowed the student to come back home late } \\
\text { on Saturday }\end{array}$ & sign. & sign. & sign. & sign. & sign. & & & sign. \\
\hline Importance of religion in respondent's life & sign. & sign. & sign. & sign. & & & sign. & sign. \\
\hline $\begin{array}{l}\text { Mass attendance by parents when the respondent } \\
\text { was } 14\end{array}$ & sign. & sign. & sign. & sign. & & & & sign. \\
\hline Body mass index at survey & sign. & & & sign. & & & & \\
\hline Had at least three health problems during teens & sign. & & sign. & sign. & sign. & & sign. & sign. \\
\hline Satisfied with own physical appearance during teens & & & & sign. & & sign. & sign. & \\
\hline Diploma score at junior/senior high school & & & & & sign. & sign. & sign. & sign. \\
\hline Type of high school attended & sign. & sign. & sign. & & sign. & sign. & sign. & sign. \\
\hline Number of covariate statistically connected $(p<0.1)$ & 8 & 7 & 8 & 8 & 10 & 8 & 8 & 13 \\
\hline $\begin{array}{l}\text { Number of covariates statistically connected in both } \\
\text { surveys }\end{array}$ & 6 & & 5 & & 7 & & 7 & \\
\hline
\end{tabular}

negatively and significantly associated with the number of partners in 2000 (but this was not found to be significant in 2017). In 2017, having two parents who frequently attended mass was negatively associated with having had multiple partners. A working mother (when the participant was aged between 14-15), parental divorce, reaction to parental rules throughout adolescence, and parents allowing the student to return home late on Saturday evenings became significant only in 2017. All of these indicators illustrate that greater permissiveness, or a decreased parental presence, leads to a higher chance of having more than three partners.

The goal of the analyses presented in this sub-section was only exploratory. The last two rows of Table 6 illustrate the existence of many contextual and individual factors associated with the rapidly changing sexual behaviours considered in this paper. Our results offer input for future studies-ad hoc research aimed at a better understanding of the determinants of the change.

\section{Conclusions}

With a focus on gender differences, this paper sought to illustrate major changes in the sexual behaviour and opinions of young Italian university students over the last two 
decades. Regarding the four research questions, several key findings emerged in terms of the changes in sexual opinions and behaviour of young men and women over a period of almost 20 years.

The first important result is an observable change in the sexuality of Italian students between 2000 and 2017. Primarily, we found also in Italy the indicators of a modernisation already experienced in North-western Europe. Along with the reduction in age at first intercourse, both homosexual and casual sex and acceptance of sexual freedom have increased. We noted a 'closure' of the territorial differences within Italy concerning the age at first intercourse for women. In 2000, female students' first sexual intercourse took place 3 years later than that of their male peers in Calabria and Sicily (both southern regions). In 2017, both Sicilian and Calabrian men and women had their first sexual intercourse between the ages of 17 and 18-in line with the national average. The south of Italy is approaching the north in terms of conjugal, sexual, reproductive, and fertility behaviour. Our results can confirm this process.

Regarding gender patterns, we found a bi-directional change for behaviour and opinions. In the past, most Italian men experienced their first sexual intercourse outside of an intimate relationship, while the vast majority of Italian women had their first intercourse inside of stable relationships, typically close to, or just after, marriage. There was indeed a sizeable gender gap. In the period between 2000 and 2017, we observed the feminisation of the sexual behaviour of males within couples. First sexual intercourse occurred increasingly often with a woman of a similar age and within the context of an intimate relationship. First sexual intercourse is now rarely-as it was in the past-an 'initiation'.

Furthermore, once in a couple, young men tended to be less likely to betray their partners, indicating again that their behaviour has been converging with that of their female counterparts. Moreover, the participants' opinions confirm that sexual fidelity is increasingly considered indispensable for a healthy couple relationship. This change in the opinions and behaviours of young Italians follows that observed among young Finns and Britons. The intolerance of betrayal has become a key feature of contemporary sexual morality (Kontula, 2009; Mercer et al., 2013). The growing hostility towards sexual betrayal may well be related to the value changes induced by the intimacy revolution: affection and mutual attraction have become the fundamental elements for couples. If forming part of a couple is essentially a reciprocal choice, betrayal cannot be easily tolerated or forgiven.

It would be interesting to understand (in a study focusing on the relationship between sexual and demographic behaviour) whether the growth in break-ups in developed countries is somehow linked to an increasing intolerance of betrayal. Combining these results with the students' opinions, a 'dual-mode' pattern seems to be emerging among both males and females. When one is single, one is allowed to have more partners, but when one is in an emotional relationship, sexual fidelity is the 'social' norm.

The second direction of change relates to women. We noted a masculinisation of women's sexual life courses in terms of their behaviour and certain opinions outside of a couple relationship. We noted a net drop in females expecting other females to keep their virginity status until marriage, and their acceptance of casual sex has doubled over the, relatively short, study period. Moreover, the number of occasional partners a female tends to have has increased substantially. Overall, the social norm that a single 
female should avoid casual sex has not yet been overturned-a notion in line with findings from other countries (e.g. for the UK, see Petersen and Hyde, 2011). Nevertheless, there is an existent progressive shift by females from traditional gender roles in this sphere, which is reflected in their behaviour. What are the health consequences of these changes? A sharp rise in condom use during first sexual intercourse had already occurred in Italy for those born in the 1970s and '80s as a result of campaigns against the AIDS epidemic (Barbagli et al., 2010, p. 81). This popularisation of contraception is in line with Italian fertility and abortion rates for individuals aged 15-24-which are among the lowest in Europe (Loghi et al., 2013, p. 100; UN 2015). However, the increase in casual sex during the past two decades seems to be correlated with a marked increase among young men, but most particularly among young women having unprotected sex with occasional partners and in the contraction of STDs.

Opinions concerning homosexuality and non-heterosexual behaviour deserve a special mention. The proportion of people who had experienced homosexual encounters (or rather, felt sufficiently confident to declare them) increased from 2000 to 2017, especially among females. In 2017, homosexuality and bisexuality among Italian university students appeared to be especially popular among women. While acceptance of same-sex partnerships increased among males, this was found to be higher among females. Again, this pattern mirrors that observed in Finland and the UK during the 2000s (Kontula, 2009, pp. 65-69; Mercer et al., 2013). The pattern is likely to be the product of greater sexual freedom for females outside of couples as, for them, the change is more closely related to behaviour than to sexual identity. For certain, it is no easy task to ascertain whether these differences stem from actual changes or from a variation in the respondents' inclination to report on their opinions and behaviour on this matter, especially among men (Caltabiano and Dalla-Zuanna, 2013). Females' persistent acceptance of homosexuality, however, is in line with a national survey on this issue conducted by the Italian Statistical Office in 2011 (Istat, 2012). Our study observes that male students have also become more likely to approve of homosexuality over time, especially among females.

Additionally, we uncovered a persistent, deep-rooted existence of double standards in male sexual opinions. Although it was less marked in 2017 than in 2000, many male students still approved of, or rejected, certain sexual behaviours according to the sex of the individual. Conversely, sexual double standards almost disappeared among female students between 2000 and 2017. Prior studies have suggested different norms for men and women regarding the first sexual intercourse (Billari and Mencarini, 2004), and a recent qualitative study observed the persistence of double standards among Italian men (Ferrero Camoletto, 2014). Our study confirms these findings for 2017.

Finally, regarding the determinants of sexual behaviour, our findings suggest that continuity is more prevalent than change. However, there are exceptions to this rule. Notably, parental presence at home, along with permissiveness, appears to be more strongly positively associated with female multi-partner sexual intercourse in 2017 than in 2000. Additional research is required to better theoretically and empirically target the changing determinants of sexual opinions and behaviours of Italian university students.

Our study is not without limitations. First, the specificity of the sample and the lack of data on certain sexual practices (such as oral and anal sex, or orgasms and sexual pleasure) are two important limits. Second, our data is not representative of the entire 
population of Italian young adults. More traditional sexual opinions and behaviour (i.e. a lower prevalence of homosexual experiences and postponed first sexual intercourse) are over-represented in our data in comparison with the population as a whole (see Appendix). We believe that our findings could benefit from being complemented by others stemming from different data collection methods, possibly on smaller samples, and employing other techniques (such as open questions and in-depth interviews). Third, it is difficult to determine with certainty whether spatial or temporal differences are due to actual behavioural changes or to a variation in the respondents' admissions (Caltabiano and Dalla-Zuanna, 2013). This is often a problem with comparative surveys when ethical, or socially sensitive, issues are in question. The diffusion and acceptance of new sexual practices should have led to a reduction in the social desirability bias.

To conclude, in the first two decades of the twenty-first century, Italian students followed a similar pattern to that which has previously been observed in North-western Europe and English-speaking countries. Generally, even if female and male attitudes are closer than they were at the beginning of the century (Bertone, 2010), we have not observed complete gender convergence. The early stages of sexual life (first sexual non complete experience, first relationship, and first sexual intercourse) take place at similar ages and in similar ways between both sexes. However, casual sex is still more common among males, who are also far more likely to use pornography often, talk more about sex with their friends, and masturbate more regularly than their female peers. The differences between males and females in terms of opinions are also profound. Men are more open to casual sex and affairs and are more likely to hold double standards. Overall, while the gap between men and women narrowed significantly by 2017, it was still certainly, present.

In social research on sexuality, four main different meanings attributed to sex have been suggested: ascetic, procreative, affective, and hedonistic (Barbagli et al. 2010, pp. 11-12; DeLamater 1981). Ascetic refers to the voluntary renunciation of sexual activity; procreative identifies the exclusive purpose of sex as being to bear children within marriage; affective concerns sexual activity being a reciprocal expression of love between partners, as well as to consolidate the relationship; and, finally, hedonistic indicates the main purpose of sexual activity is to achieve physical pleasure. Our results suggest that now (and likely in the near future) the ascetic and procreative meanings are, and will be, less and less widespread. However, in Italy-as elsewhere-the trend is not towards a sort of bond-free sexuality linked only to hedonism and physical attraction. This may be partially true during the years when people are unbound by couple affective relationships, but it is certainly not the case for people in couples, where the affective meaning prevails for both genders.

\section{Supplementary information}

Supplementary information accompanies this paper at https://doi.org/10.1186/s41118-020-00085-4

Additional file 1: Sampling Method, Questionnaire, and Covariates. 


\section{Authors' contributions}

AM conceived the study, participated in its design and coordination, and helped to draft the manuscript. MC conceived the study, participated in its design and coordination, and helped to draft the manuscript. GDZ conceived the study, participated in its design and coordination, and helped to draft the manuscript. DV conceived the study, participated in its design and coordination, and helped to draft the manuscript. All authors read and approved the final manuscript.

\section{Funding}

The project is funded by the Italian Ministry of University and Research, 2017 MiUR-PRIN Grant Prot. N. 2017W5B55Y (PI: Daniele Vignoli).

\section{Availability of data and materials}

Data: The datasets used and/or analysed during the current study are available from the corresponding author on reasonable request.

\section{Competing interests}

The authors declare that they have no competing interests.

\section{Author details}

'Department of Statistics, Computer Science, Applications "G. Parenti" (DiSIA), University of Florence, Viale Morgagni 59, 50134 Florence, Italy. ${ }^{2}$ Department of Economics, University of Messina, Messina, Italy. ${ }^{3}$ Departement of Statistical Sciences, University of Padova, Padua, Italy.

Received: 30 September 2019 Accepted: 18 June 2020

Published online: 15 July 2020

\section{References}

Allen, E. S., \& Baucom, D. H. (2006). Dating, marital, and hypothetical extradyadic involvements: How do they compare? The Journal of Sex Research, 43(4), 307-317.

Allison, R., \& Risman, B. J. (2013). A double standard for "hooking up": How far have we come toward gender equality? Social Science Research, 42, 1191-1206. https://doi.org/10.1016/j.ssresearch.2013.04.006.

Ariès, P. (1960). L'enfant et la Vie Familiale sous l'Ancien Régime [centuries of childhood: A social history of family life]. Paris: Seuil. Ariès, Ph., and Duby, G. (1985-87). Histoire de la Vie Privée [A history of private life]. Paris: Seuil.

Barbagli, M., Dalla-Zuanna, G., \& Garelli, F. (2010). La Sessualità degli Italiani [the sexuality of Italians]. Bologna: II Mulino.

Belletti, F., Boffi, P., \& Pennati, A. (2007). Convivenze all'taliana. Motivazioni, caratteristiche e vita quotidiana delle coppie di fatto [Italian-style coexistence. Motivations, characteristics and daily life of de facto couples]. Milano: Paoline Editoriale Libri.

Bertone, C. (2010). Sessualità maschili e femminili, fra convergenze e nuove divergenze [masculine and feminine sexuality, between convergence and new differences]. In M. Barbagli, G. Dalla-Zuanna, \& F. Garelli (Eds.), La sessualità degli italiani Italiani [the sexuality of Italians] (pp. 207-234). Bologna: II Mulino.

Billari, F. C., Caltabiano, M., \& Dalla-Zuanna, G. (Eds.). (2007). Sexual and affective behaviour of students. An international research. Padua: Cleup.

Billari, F. C., \& Mencarini, L. (2004). Norms and sanctions on sexual life. In G. Dalla-Zuanna \& C. Crisafulli (Eds.), Sexual behaviour of Italian students (pp. 361-379). Messina: University of Messina.

Bordini, G. S., \& Sperb, T. M. (2013). Sexual double standard: A review of the literature between 2001 and 2010. Sexuality and Culture, 17, 686-704. https://doi.org/10.1007/s12119-012-9163-0.

Bozon, M., \& Kontula, O. (1998). Sexual initiation and gender in Europe. A crosscultural analysis of trends in the twentieth century. In M. Hubert, N. Bajos, \& T. Sandfort (Eds.), Sexual behaviour and HIV/AIDS in Europe. Comparisons of national surveys (pp. 37-67). London: UCL Press.

Bradshaw, C., Kahn, A. S., \& Saville, B. K. (2010). To hook up or date: Which gender benefits? Sex Roles, 62, 661-669. https://doi. org/10.1007/s11199-010-9765-7.

Braithwaite, S. R., Coulson, G., Keddington, K., \& Fincham, F. D. (2015). The influence of pornography on sexual scripts and hooking up among emerging adults in college. Archives of Sexual Behaviour, 44, 111-123. https://doi.org/10.1007/s10508014-0351-X.

Brown, N. R., \& Sinclair, R. C. (1999). Estimating number of lifetime sexual partners: Men and women do it differently. The Journal of Sex Research, 36(3), 292-297. https://doi.org/10.1080/00224499909551999.

Caltabiano, M. (2006). The first romantic relationship of adolescents: A comparative analysis. Genus, 61(2), 141-160.

Caltabiano, M., \& Dalla-Zuanna, G. (2013). A comparison of survey techniques on sensitive sexual behaviour in Italy. Journal of Sex Research, 50, 537-547. https://doi.org/10.1080/00224499.2012.674573.

Caltabiano, M., Dalla-Zuanna, G., \& Rosina, A. (2006). Interdependence between sexual debut and church attendance in Italy. Demographic Research, 14(19), 453-484. https://doi.org/10.4054/DemRes.2006.14.19.

Conley, T. D., Ziegler, A., \& Moors, A. C. (2013). Backlash from the bedroom stigma mediates gender differences in acceptance of casual sex offers. Psychology of Women Quarterly, 37, 392-407. https://doi.org/10.1177/0361684312467169.

Crawford, M., \& Popp, D. (2003). Sexual double standards: A review and methodological critique of two decades of research. The Journal of Sex Research, 40(1), 13-26. https://doi.org/10.1080/00224490309552163.

Cucci, G., Olivari, M. G., \& Confalonieri, E. (2017). Adolescenti e sexting: Una review della letteratura. Maltrattamento e abuso allinfanzia, 2, 119-140. https://doi.org/10.3280/MAL2017-002007.

Dalla-Zuanna, G., \& Crisafulli, C. (Eds.). (2004). Sexual behavior of Italian students. Messina: University of Messina.

Dalla-Zuanna, G., De Rose, A., \& Racioppi, F. (2005). Low fertility and limited diffusion of modern contraception in Italy during the second half of the twentieth century. Journal of Population Research, 22, 21-48 www.jstor.org/stable/41110821.

Dalla-Zuanna, G., \& Micheli, G. A. (Eds.). (2004). Strong family and low fertility: A paradox? New perspectives in interpreting contemporary family and reproductive behaviour. Berlin: Springer. 
De Rose, A., \& Strozza, S. (Eds.). (2015). Rapporto sulla Popolazione - L'Italia nella Crisi Economica [population report - Italy in the economic crisis]. Bologna: il Mulino.

DeLamater, J. (1981). The social control of sexuality. Annual Review of Sociology, 7(1), 263-290.

Dotti Sani, G., \& Treas, J. (2016). Educational gradients in parents' child-care time across countries, 1965-2012. Journal of Marriage and Family, 78(4), 1083-1096.

Eisenberg, M. (2001). Differences in sexual risk behaviors between college students with same-sex and opposite-sex experience: Results from a national survey. Archives of Sexual Behavior ,30, 575-589. https://doi.org/https://doi.org/10. 1023/A:1011958816438.

England, P., \& Bearak, J. (2014). The sexual double standard and gender differences in attitudes toward casual sex among US university students. Demographic Research, 30, 1327-1338. https://doi.org/10.4054/DemRes.2014.30.46.

Ferrero Camoletto, R. (2014). Fare sesso, fare genere? Un'analisi dei copioni sessuali dei giovani uomini al primo rapporto sessuale [Doing sex, doing gender? Exploring young men's sexual scripts at first intercourse]. Rassegna Italiana di Sociologia, LV (4,), 705-734. doi: https://doi.org/10.1423/78747.

French, S. E., \& Holland, K. J. (2013). Condom negotiation strategies as a mediator of the relationship between self-efficacy and condom use. The Journal of Sex Research, 50, 48-59. https://doi.org/10.1080/00224499.2011.626907.

Gabrielli, G., \& Borgoni, R. (2007). Age at first sexual intercourse in Italy: A geographical approach. Genus, 63(1/2), $149-183$.

Garton, S. (2004). Histories of sexuality. Antiquity to sexual revolution. New York: Routledge.

Giddens, A. (1990). The consequences of modernity. Cambridge: Cambridge Polity Press.

Giddens, A. (1992). The transformation of intimacy sexuality, love and eroticism in modern societies. Stanford, USA: Stanford University Press.

Gómez Berrocal, M., Vallejo-Medina, P., Moyano,N., and Sierra, J. C. (2019) Sexual double standard: A psychometric study from a macropsychological perspective among the spanish heterosexual population. Frontiers in Psychology, 10, 1664-1078. doi: https://doi.org/https://doi.org/10.3389/fpsyg.2019.01869.

Goode, E. and Haber, L. (1977). Sexual correlates of homosexual experience: An exploratory study of college women. The Journal of Sex Research, 13, 12-21. doi: https://doi.org/https://doi.org/10.1080/00224497709550956

Goodson, P., McCormick, D., \& Evans, A. (2001). Searching for sexually explicitmaterials on the internet: An exploratory study of college students' behaviorand attitudes. Archives of Sexual Behavior, 30, 101-111. https://doi.org/10.1023/A:1002724116437.

Guetto, R., Luijkx, R., and Scherer, S. (2015). Religiosity, gender attitudes and women's labour market participation and fertility decisions in Europe. Acta Sociologica, 58(2), 155-172. doi: https://doi.org/https://doi.org/10.1177/0001699315573335.

Hines, D. A. (2007). Predictors of sexual coercion against women and men: A multilevel, multinational study of university students. Archives of Sexual Behaviour, 36(3), 403-422. https://doi.org/10.1007/s10508-006-9141-4.

Istat (2012). La popolazione omosessuale nella società italiana. Retrieved from: https://www.istat.it/it/archivio/62168

Keller, D. (1959). Personality aspects related to misinformation about sex among college students. Science Education, 43, 156163. https://doi.org/https://doi.org/10.1002/sce.3730430216

Kontula, O. (2009). Between sexual desire and reality. The evolution of sex in Finland. Helsinki: Publications of the Population Research Institute, vol. 49.

Kreager, D.A., Staff, J., Gauthier, R., Lefkowitz, E. S., and Feinberg, M. E. (2016). The double standard at sexual debut: Gender, sexual behavior and adolescent peer acceptance. Sex Roles, 75(7-8), 377-392. doi: https://doi.org/https://doi.org/10.1007/ s11199-016-0618-x

Kuperberg, A., \& Walker, A. M. (2018). Heterosexual college students who hookup with same-sex partners. Archives of Sexual Behavior, 47(5), 1387-1403. https://doi.org/10.1007/s10508-018-1194-7.

Laumann, E. O., Gagnon, J. H., Michael, R. T., \& Michael, S. (1994). The social organization of sexuality. Sexual practices in the United States. Chicago: University of Chicago Press.

Lefkowitz, E. S., Vasilenko, S. A., Wesche, R., \& Maggs, J. L. (2018). Changes in diverse sexual and contraceptive behaviors across college. The Journal of Sex Research. https://doi.org/10.1080/00224499.2018.1499854.

Lesthaeghe, R., and van de Kaa, D.J. (1986). Twee demografische transities? [Two demographic transitions?] In D.J. van de Kaa, D.J. and R. Lesthaeghe (eds) Bevolking: groei en krimp. Special issue of Mens en Maatschappij (pp. 9-24). Van Loghum Slaterus, Deventer.

Loghi, M., Spinelli, A., and D'Errico, A. (2013). Il declino dell'aborto volontario [The decline of abortion]. In G. Dalla-Zuanna and A. De Rose (eds.) Rapporto sulla popolazione. Sessualità e riproduzione nell'talia contemporanea [Population report. Sexuality and reproduction in contemporary Italy] (pp. 97-116). Bologna: il Mulino.

Lomazzi, V. (2016). Donne e sfera pubblica. I valori degli europei a confronto.[Women and the public sphere. The values of Europeans compared] Milan: Franco Angeli.

Marks, M. J., \& Fraley, R. C. (2006). Confirmation bias and the sexual double standard. Sex Roles, 54, 19-26. https://doi.org/10. 1007/s11199-006-8866-9.

McAnulty, R., \& Brineman, J. (2007). Infidelity in dating relationships. Annual Review of Sex Research, 18, 94-114. https://doi.org/ 10.1080/10532528.2007.10559848.

Mercer, C. H., Tanton, C., Prah, P., Erens, B., Sonnenberg, P., Clifton, S., Macdowall, W., Lewis, R., Field, N., Datta, J., Copas, A. J., Phelps, A., Wellings, K., \& Johnson, A. M. (2013). Changes in sexual attitudes and lifestyles in Britain through the life course and over time: Findings from the National Surveys of sexual attitudes and lifestyles (Natsal). The Lancet, 382, 1781-1794. https://doi.org/ 10.1016/S0140-6736(13)62035-8.

Mitchell, K. R., Mercer, C. H., Prah, P., Clifton, S., Tanton, C., et al. (2019). Why do men report more opposite-sex sexual partners than women? Analysis of the gender discrepancy in a British national probability survey. The Journal of Sex Research, 56(1), 1-8.

Norona, J. C., Preddy, T. M., \& Welsh, D. P. (2015). How gender shapes emerging adulthood. The Oxford Handbook of Emerging Adulthood. Doi. https://doi.org/10.1093/oxfordhb/9780199795574.013.13.

Olmstead, S. B., Billen, R. M., Conrad, K. A., Pasley, K., \& Fincham, F. D. (2013). Sex, commitment, and casual sex relationships among college men: A mixed-methods analysis. Archives of Sexual Behaviour, 42, 561-571. https://doi.org/10.1007/ s10508-012-0047-z.

Petersen, J. L., \& Hyde, J. S. (2010). A meta-analytic review of research on gender differences in sexuality, 1993-2007. Psychological Bullettin, 136(1), 21-38. https://doi.org/10.1037/a0017504. 
Petersen, J. L., \& Hyde, J. S. (2011). Gender differences in sexual attitudes and behaviors: A review of meta-analytic results and large datasets. The Journal of Sex Research, 48(2-3), 149-165. https://doi.org/10.1080/00224499.2011.551851.

Pirani, E., and Vignoli, D. (2016). Changes in the satisfaction of cohabitors relative to spouses over time. Journal of Marriage and Family, 78(3): 598-609. https://doi.org/10.1111/jomf.12287.

Pitts, M., and Rahman, Q. (2001). Which behaviours constitute 'having sex' among university students in the UK? Archives of Sexual Behaviour, 30(2), 169-176. https://doi.org/10.1023/A:1002777201416.

Reiss, I. L. (1956). The double standard in premarital sexual intercourse: A neglected concept. Social Forces, 34(3), 224-230. https://doi.org/10.2307/2574041.

Romito, P., \& Beltramini, L. (2011). Watching pornography: Gender differences, violence and victimization. An exploratory study in Italy. Violence Against Women, 17, 1313-1326.

Rosina, A., \& Fraboni, R. (2004). Is marriage losing its centrality in Italy? Demographic Research, 11, 149-172. https://doi.org/10. 4054/DemRes.2004.11.6.

Scarcelli, C. M. and Stella R. (2019). The mediated erotic lover. The role of pornography in the negotiation of gender roles and desire amongst Italian heterosexual couples. Journal of Gender Studies, 1-11. https://doi.org/10.1080/09589236.2019. 1670149.

Schröder, C. (2008). The influence of parents on cohabitation in Italy - insights from two regional contexts. Demographic Research, 19(48), 1693-1726. https://doi.org/10.4054/DemRes.2008.19.48

Simon, W., and Gagnon, J. H. (1984) Sexual scripts. Society, 22(1), 53-60. https://doi.org/10.1007/BF02701260.

Simon, W., and Gagnon, J. H. (1986) Sexual scripts: Permanence and change. Archives of Sexual Behavior, 15, 97-120. https:// doi.org/10.1007/BF01542219.

Simon, W., and Gagnon, J. H. (2003) Sexual scripts: Origins, influences and changes. Qualitative Sociology, 26, 491-497. https:// doi.org/10.1023/B:QUAS.0000005053.99846.e5

Sprecher, S. (2014). Evidence of change in men's versus women's emotional reactions to first sexual intercourse: A 23-year study in a human sexuality course at a Midwestern university. The Journal of Sex Research, 51(4), 466-472. https://doi.org/ 10.1080/00224499.2013.867923.

Stinson, R. (2010). Hooking up in young adulthood: A review of factors influencing the sexual behaviour of college students. Journal of College Student Psychotherapy, 24(2), 98-115. https://doi.org/10.1080/87568220903558596

UN, Department of Economic and Social Affairs, Population Division (2015). World fertility patterns 2015 - data booklet (ST/ ESA/SER.A/370). Retrieved from: https://www.un.org/en/development/desa/population/publications/pdf/fertility/worldfertility-patterns-2015.pdf.

Vignoli, D., Matysiak, A., Styrc, M., \& Tocchioni, V. (2018). The positive impact of women's employment on divorce: Context, selection, or anticipation? Demographic Research, 38, 1059-1110. https://doi.org/10.4054/DemRes.2018.38.37.

Vignoli, D., \& Salvini, S. (2014). Religion and union formation in Italy: Catholic precepts, social pressure, and tradition. Demographic Research, 31, 1079-1106. https://doi.org/10.4054/DemRes.2014.31.35.

Walsh, J. L., Fielder, R. L., Carey, K.B., and Carey, M. P. (2014). Dual method use among a sample of first-year college women. Perspective on Sexual and Reproductive Health, 46(2), 73-81. https://doi.org/10.1363/46e1014.

Weeden, J., \& Sabini, J. (2007). Subjective and objective measures of attractiveness and their relation to sexual behaviour and sexual attitudes in university students. Archives of Sexual Behaviour, 36(1), 79-88. https://doi.org/10.1007/s10508-006-9075-x.

Wellings, K., Collumbien, M., Slaymaker, M., Singh, S., Hodges, Z., Patel, D., \& Bajos, N. (2006). Sexual behaviour in context: A global perspective. The Lancet, 368, 1706-1728. https://doi.org/10.1016/S0140-6736(06)69479-8.

Wells, B. E., \& Twenge, J. M. (2005). Changes in young people's sexual behavior and attitudes, 1943-1999: A cross-temporal meta-analysis. Review of General Psychology, 9(3), 249-261. https://doi.org/10.1037/1089-2680.9.3.249.

WHO (2016). Growing up unequal: gender and socioeconomic differences in young people's health and well-being: Health behaviour in school-aged children (HBSC study): international report from the 2013/2014 survey. Retrieved from: http://www. euro.who.int/_data/assets/pdf_file/0003/303438/HSBC-No.7-Growing-up-unequal-Full-Report.pdf.

Wiederman, M. W. (1997). The truth must be in here somewhere: Examining the gender discrepancy in self-reported lifetime number of sex partners. The Journal of Sex Research, 34(4), 375-386. https://doi.org/10.1080/00224499709551905.

Zaikman, Y., \& Marks, M. J. (2017). Promoting theory-based perspectives in sexual double standard research. Sex Roles, 76(7-8), 407-420. https://doi.org/10.1007/s11199-016-0677-z.

Zelin, A. I., Erchull, M. J., \& Houston, J. R. (2015). Is everybody doing it? Perceptions and misperceptions of sexual behavior in the college freshman population. Gender Issues, 32, 139-163. https://doi.org/10.1007/s12147-015-9134-5.

\section{Publisher's Note}

Springer Nature remains neutral with regard to jurisdictional claims in published maps and institutional affiliations. 